\title{
Reevaluation of Factors Affecting Bunch Drop in Date Palm
}

\author{
Yuval Cohen \\ Institute of Plant Sciences, Agricultural Research Organization, The Volcani \\ Center, Bet Dagan 50250, Israel
}

Stanley Freeman and Aida Zveibil

Department of Plant Pathology and Weed Research, Institute of Plant

Protection, Agricultural Research Organization, The Volcani Center, Bet Dagan 50250, Israel

Rachel Ben Zvi

Zemach Regional Agriculture Research Center, Jordan Valley 15132, Israel

Yaakov Nakache

Eden Experimental Station, Bet Shean Valley, Israel

Shimon Biton

Israeli Ministry of Agriculture and Rural Development, Extension Service

Victoria Soroker ${ }^{1}$

Department of Entomology, Institute of Plant Protection, Agricultural Research Organization, The Volcani Center, P.O. Box 6, Bet Dagan 50250, Israel

Additional index words. cross-cut, deficit irrigation, Fusarium proliferatum, Phoenix dactylifera, $\mathrm{V}$-cut

Abstract. Severe damage has been observed in Israeli date palm (Phoenix dactylifera $\mathbf{L}$.) plantations of the Medjool cultivar as a result of drying and dropping of fruit bunches. Both fractures and rot occurred during peduncle (fruit stalk) development at proximal points located deep within the crown. The phenomenon has been previously described as "cross-cut" or "V-cut." The present study aimed to characterize the phenomenon and identify the main causal factors. Annual surveys have revealed high levels of fruit bunch drop in all 'Medjool' cultivation areas in Israel. Arenipses sabella and other insects were only occasionally detected in the damaged fruit stalks. Similar damage levels observed in insecticide-treated and untreated plots suggested that insects were not directly responsible for this phenomenon. Tissue decay was detected in many of the freshly fallen fruit stalks. The pathogenic fungus, Fusarium proliferatum, was detected in most of the necrotic fruit stalks. Fusarium proliferatum isolates from infected fruit stalks generated necrotic lesions in fruit stalk tissue in vitro. However, fungicide treatments on trees in the orchards were ineffective in reducing bunch drop. On the other hand, restraining the growth rate of the fruit stalk, by reducing irrigation levels (to $20 \%$ ) during the period of fruit stalk development and growth, significantly reduced bunch drop levels in most of the examined plots. These data suggest that bunch drop in 'Medjool' date palm is caused mainly by physiological disorders related to fruit stalk development and growth.

The inflorescences of date palm (Phoenix dactylifera) develop within the crown of the

\footnotetext{
Received for publication 7 Dec. 2009. Accepted for publication 29 Mar. 2010

This research was supported by the Israeli Date Palm Growers' Association, grant no. 131-1364.

We acknowledge the date growers of Kalia, Beit Haarava, Almog, and Mizpe Shalem for their help and collaboration; Effi Tripler for critically reviewing the manuscript; and Shlomit Levski and Raia Korchinsky for their technical assistance. We also thank the anonymous reviewers for their fruitful comments.

This manuscript is contribution \#518/09 from the Volcani Center, Israel.

${ }^{1}$ To whom reprint requests should be addressed; e-mailsorokerv@volcani.agri.gov.il.
}

tree, at the base of the leaves, from meristems located as deep as $1 \mathrm{~m}$ within the upper part of the trunk (Tomlinson, 1990; Zaid and De Wet, 1999). Each inflorescence is enclosed by a single hard, sealed protective cover, the prophyll (commonly called spathe). The inflorescence is branched with numerous first-order rachilae immerging from the main inflorescence stem, the peduncle (called "fruit stalk" by farmers) (Chao and Krueger, 2007; Dransfield et al., 2008; Tomlinson, 1990). The fruit stalk continues to elongate for several weeks after fertilization (Chao and Krueger, 2007; Dransfield, et al., 2008). Fruit stalk drying and rot in date palm has been observed for decades and was described as early as the 1930s (Bliss, 1937). This phenomenon, previously described as "cross-cut" or "V-cut," is expressed as cuts in the fruit stalk, which cause the drying and dropping of fruit bunches. These symptoms have been commonly observed in many dategrowing regions, particularly in the Sayer and Khadrawi cultivars and occasionally in 'Dayri', 'Maktoom', and 'Halawi' (Bliss, 1937; Brown and Butter, 1936; Carpenter and Elmer, 1978; Stoler, 1977; Zaid et al., 1999). Damage appears intermittently, but, in specific years, can cause up to $25 \%$ crop loss (Bliss, 1937). Cross-cuts are most commonly found in relatively slowgrowing cultivars with densely arranged leaf bases and the severity of damage increases with the age of the tree (Carpenter and Elmer, 1978).

Recently, severe damage to Medjool cultivar resulting from bunch drop has been observed in Israel. In some areas, up to eight bunches, out of a total of 25 to 30 , were lost from each tree, which may reach up to $30 \%$ yield loss. Both fractures and rot occurred during fruit stalk development deep within the crown.

Three major causal agents have been suggested as possible factors in this phenomenon: 1) mechanical cracks of unclear origin occurring in the soft tissues of the fast-growing fruit bunch (Bliss, 1937); 2) pathogen infection [necrosis has often been observed at the cuts, suggesting the involvement of fungal pathogens in the process (Bliss, 1937)]. However, it is not clear whether these pathogens play a primary or secondary role in this phenomenon; and 3) larvae of the greater date moth (Arenipses sabella Hampson) overwintering within the bases of the leaves within the date crown and feeding on developing fruit stalks (Okko, 2004).

Bliss (1937) suggested that Fusarium sp. may be involved in the process. Recently, Fusarium proliferatum has been isolated from roots and leaves of declining date palm (Abdalla et al., 2000) and other palm species (Armengo et al., 2005), but these studies have not mentioned any role for this pathogen in fruit bunch drop.

The aims of this study were to characterize the phenomenon of bunch drop in 'Medjool' date palm and elucidate the role of the previously mentioned factors in this phenomenon.

\section{Materials and Methods}

Survey of bunch drop in the major dategrowing areas of Israel. During the years 2005 to 2008 , a survey was conducted in date palm plantations along the Jordan River and Arava Rift Valley using a questionnaire. Major date farmers (50 growers) were requested to report the average number of fallen bunches in each of their plots, the total number of trees in each plot, and the trees' ages. Substantial data were obtained only for 2007 to 2008, in which 19,200 and 22,500 trees were recorded during 2007 and 2008, respectively. The data represent $11.5 \%$ and $12.3 \%$ of the entire 'Medjool' fruit-bearing trees in Israel. The data were summarized as the average number of fallen bunches per affected plot.

Distribution of fallen bunches within specific plots. Several plots on the northern 
shore of the Dead Sea (in Kalia, Almog, Bet Haarava, and Mizpe Shalem) were selected for more detailed examination. The numbers of fallen bunches from each tree were determined each year after the development and growth of the bunches in March through June. Distribution maps of fallen bunches per tree were constructed for a plot of 386 trees in Almog and used for spatial distribution analysis in each year and among 4 consecutive years, 2005 to 2008.

Effects of insecticide and fungicide treatments on the incidence of bunch drop. All treatments were performed on five to 15 randomly distributed trees per plots in several 'Medjool' orchards on the northern shore of the Dead Sea. All plots consisted of mature fruitbearing trees at least 12 years old. A summary of the various treatments tested to reduce bunch drop is presented in Table 1. Two different preventive treatments were tested for use against the greater date moth (Arenipses sabella) and other arthropods. For the first treatment, a mixture of $0.15 \%$ Dorsan ( $48 \%$ chlorpyrifos; Luxembourg, Israel), $0.1 \%$ Match $\left(50 \mathrm{~g} \cdot \mathrm{L}^{-1}\right.$ lufenuron; CTS, Israel), and $0.1 \%$ Divipan (dichlorvos 100\%; Makhteshim, Israel) in an aqueous solution was applied as a spray $(10 \mathrm{~L}$ per tree per application) to the base of the leaves of the trees' crowns. There were three consecutive applications of this mixture. The first application was made at the end of November ( $\approx 3$ months before flowering), the second application in January (1 month before flowering), and the third application in midFebruary (when $50 \%$ of the inflorescences had emerged). The other insecticide treatment consisted of two applications of Confidor (imidacloprid $350 \mathrm{~g} \cdot \mathrm{L}^{-1}$; Bayer), $10 \mathrm{~mL}$ per tree per application (Table 1), which were equally divided and applied as an aqueous solution under the drippers during December and February of 2005 and 2006.

As part of our study, the Fusarium proliferatum strains isolated from infected tissue (see subsequently) were found to be sensitive to the fungicide prochloraz, which completely inhibited fungal growth at a concentration of $10 \mathrm{ppm}$ (data not shown). Therefore, the effect of $0.2 \%$ Octave $(46.2 \%$ prochloraz present as manganese chloride complex; Bayer) or $0.2 \%$ Sportak (45\% prochloraz; Bayer) was tested for the control of fusarium under field conditions during 4 consecutive years (2006 to 2009) (Table 1). Switch from Octave to Sportak occurred as a result of practical availability. The chemicals were applied three times by crown spraying to the bases of the trees' leaves (10 L per tree per application), once in January and twice in February.

Manipulation of irrigation levels to affect bunch drop. The effect of reduced irrigation on bunch drop was evaluated in commercial orchards in the northern Dead Sea region. The trees were spaced $9 \mathrm{~m}$ apart from one another $\left(9 \times 9 \mathrm{~m}^{2}\right.$ between trees, within and between rows) and four drippers were placed by each tree. Each dripper discharged $24 \mathrm{~L} \cdot \mathrm{h}^{-1}$. In Israel, irrigation practices are determined based on evaporation from Class A evaporation pans (Liebenberg and Zaid, 1999) using an

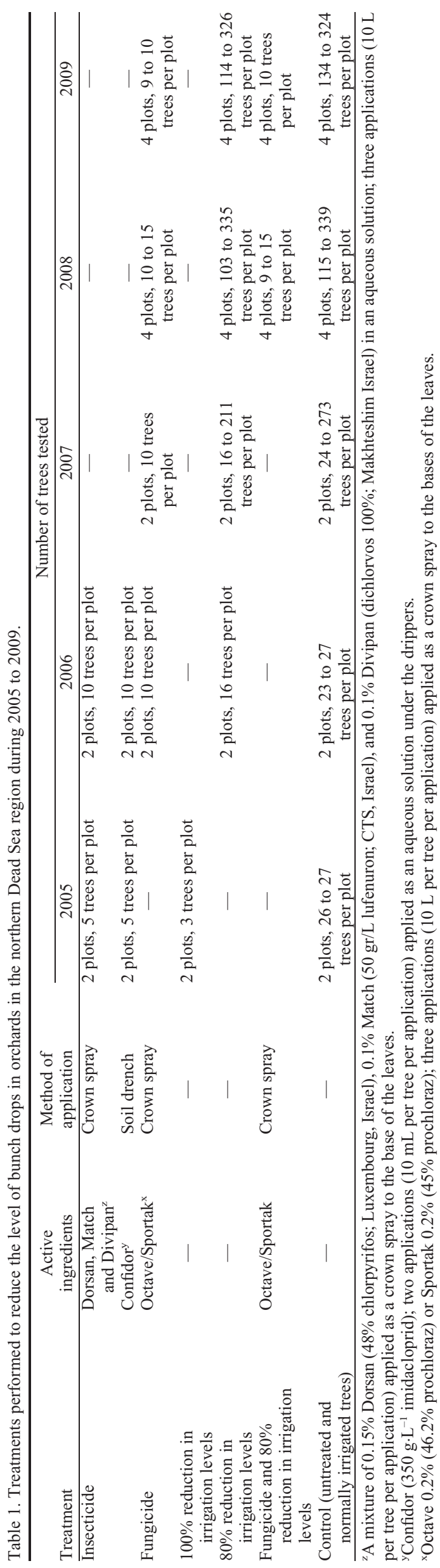

HortScience Vol. 45(6) June 2010 
empirical coefficient $(\mathrm{Kc})$ of 0.65 . During the cool season (November to April), date palm trees are irrigated once every 2 to $3 \mathrm{~d}$. On average, trees were irrigated with $\approx 220 \mathrm{~L} \cdot \mathrm{d}^{-1}$ in January and February and 330 and $450 \mathrm{~L} \cdot \mathrm{d}^{-1}$ during March and April, respectively. In a preliminary experiment, conducted in 2005, irrigation of three trees in two different commercial plots was stopped for 4 months, starting 2 months before the estimated appearance of the first bunches (end of December) to the end of rapid bunch stalk elongation (mid- to late April) (Table 1). During 2006 to 2009, along with the commercial irrigation management, selected trees or plots were irrigated with only $20 \%$ of the standard water levels from December through the middle of April (Table 1). In 2006, 16 trees (in $4 \times 4$ squares) in two different orchards received reduced volumes of irrigation water $(20 \%$ of the standard amount), and their bunch drop and growth were compared with that of 40 control trees that received the standard amounts of water. During 2007, 211 trees with reduced irrigation $(20 \%$ of the standard amount) were compared with 273 normally irrigated trees. During 2008 to 2009, the experiment was expanded to four orchards. In each of these orchards, plots of 100 to 330 trees with reduced irrigation ( $20 \%$ of the standard amount) were compared with plots with similar numbers of normally irrigated trees (controls) (Table 1). In 2009, soil water matrix potential was measured using tensiometers placed $0.4 \mathrm{~m}$ from the trees at three different depths $(30,60$, and $90 \mathrm{~cm}$ ) in one control and one reducedirrigation plot. Each tensiometer was equipped with a temperature-compensated pressure transducer, which had a wireless connection to an automated data-logging device (Netafim Irrigation Inc., Israel). The rates of vegetative growth were compared for three trees from reduced and normal irrigated plots throughout the period of reduced irrigation. Flexible metal measuring tapes were physically bound to the tree's trunk at a convenient height $(\approx 1.5 \mathrm{~m}$ from the ground). The tips of these flexible rulers were attached by strings to the tips of the rachis of the spear leaves on top of the trees' crowns. As the expanding leaves grew vertically, they pulled the strings showing the exact leaf expansion on the flexible rulers (Bernstein, 2004). Because young spear leaves grow strictly upward for $\approx 1$ month, to acquire 4-month records, the measured spear leaves were replaced once a month by younger ones. To monitor the growth of the inflorescences, the string was first attached to the closed prophyll (spathe) and after pollination to the fruit stalk. The measured leaf/inflorescence expansion was divided by the time between each consecutive measurement to calculate the average daily growth. Because the growth rates of both fruit stalks and spear leaves decreased on reduction of irrigation levels in 2006, further measurements were conducted on spear leaves only.

Identification of fungal pathogens associated with bunch drop. During the 2005 to 2008 growing seasons, fresh fruit stalks from various groves that showed fresh V-cuts or delayed growth were removed from the crowns and cut below the $\mathrm{V}$-cut region. Infected tissue was surface-disinfected ( $3 \% \mathrm{v} / \mathrm{v}$ sodium hypochlorite) for $1 \mathrm{~min}$, washed twice with sterile distilled water, and plated on various culture media, including potato dextrose agar and a fusarium-specific medium (Nash and Snyder, 1962). Thirty-one cultures of Fusarium proliferatum, the major fungal pathogen isolated from the infected tissue, were identified based on their morphology. Their identities were further verified through the use of a speciesspecific polymerase chain reaction (PCR) amplification method (Mulè et al., 2004). $F$. proliferatum is a known pathogen of date palm (Abdalla et al., 2000; Armengo et al., 2005). Therefore, we proceeded to investigate whether the isolated organism was associated with the bunch drop phenomenon.

Inoculations of detached fruit stalks. Three monoconidial isolates of $F$. proliferatum (F.p. 1, F.p, 19, and F.p. 23) and one control isolate of $F$. oxysporum f. sp. melonis (F.o.m. $1 / 2$, which infects muskmelon) were used for artificial inoculation of freshly harvested fruit stalks ('Medjool'). Cultures of the isolates $\left(10^{6}\right.$ conidia $\left./ \mathrm{mL}\right)$ were inoculated by placing a $20-\mu \mathrm{L}$ drop of suspension without wounding and with a superficial or deeper 2-mm wound at four different points along the central axis of the stalks. Similar water inoculations served as controls. Three replicate stalks were inoculated with each isolate and the experiment was conducted twice with the F.p. 19 and F.p. 23 isolates and once with the F.p 1 and F.o.m.1/2 isolates. The stalks were incubated in a moist chamber at $25{ }^{\circ} \mathrm{C}$ for $3 \mathrm{~d}$ before evaluation. Thereafter, percentage infection was calcu- lated according to the appearance of necrotic symptoms at each of the inoculation sites. Lesion length ( $\mathrm{mm}$ ) was also measured.

Data analysis. Differences in bunch drop levels were assessed using one- or two-way analysis of variance followed by Tukey-Kramer honestly significant different tests. Before the analysis, data were subjected to square-root transformation. The distribution of bunch drop in a plot containing 383 trees was evaluated for 4 consecutive years (2005 to 2008 ) by calculating the coefficient of dispersion (Sokal and Rohlf, 1981). The correlation between the numbers of bunch drop from each particular tree in different years was tested on square-root transformed data using the Pearson correlation.

\section{Results and Discussion}

A survey of bunch drop was conducted over 4 years (2005 to 2008). However, substantial amounts of data, from $\approx 20,000$ trees, representing $\approx 167$ ha $(11.5 \%$ to $12.3 \%$ of total 'Medjool' fruit-bearing orchards), were accumulated during the last 2 years of the survey. Figure 1 shows the average distribution of bunch drop levels per tree in different plots. In general, throughout the country, the phenomenon was more intense during 2008. However, very large variations were detected between plots. As shown in Figure 2, damage levels varied even between plots at the same location (Almog). Some plots tended to be less prone to bunch drop than others. Damage levels varied in different years. In this particular area (the northwestern shore of the Dead Sea), the damage observed in 2005 was much more severe than that observed in the
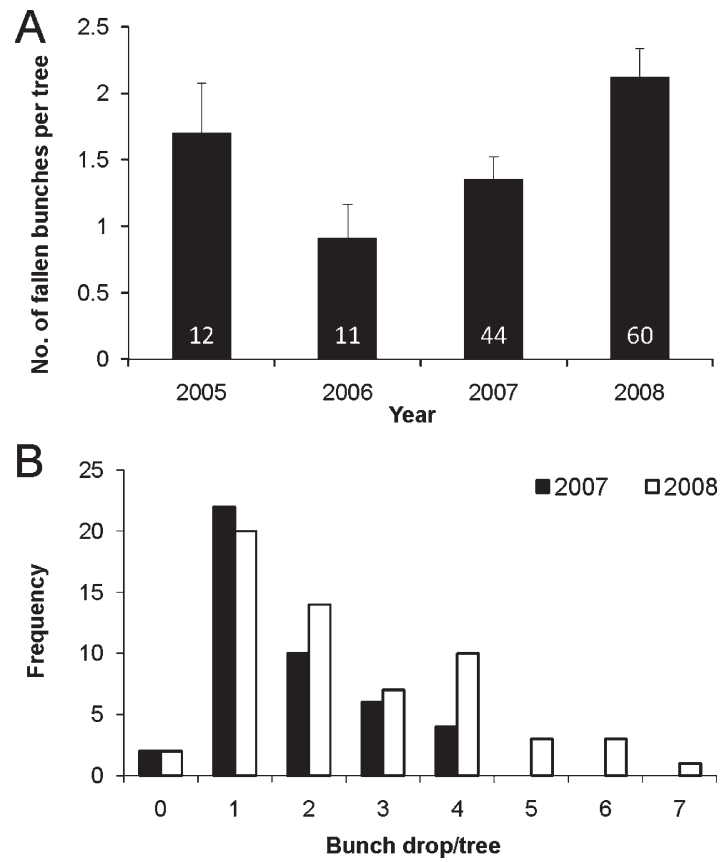

Fig. 1. Summary of field surveys conducted in various date palm orchards. (A) The data represent the average numbers of fallen bunches per tree in the affected plots as recorded during 2005 to 2008. Bars indicate SE. The numbers within the columns represent the number of plots in each year's survey. (B) Frequency distribution of orchards in which bunch drop was observed in 2007 and 2008 . 
next 4 years. We do not have a clear explanation for annual variation in the phenomena. It may be a result of some abiotic affect such as rain fall/temperature condition during the development and expansion of the fruit bunches. Palm age has been suggested as a possible factor affecting bunch drop and the phenomena was reported to increase with age (Carpenter and Elmer, 1978). In general, the data presented in Figure 2 do not support this assumption. Indeed, trees in their first years of fruiting have less fallen bunches; however, they also have significantly less inflorescences. Moreover, no clear age effect was found in the survey data. In 2007, a significant positive correlation between the palm age and tree age was found (Pearson correlation, $r=0.74, \mathrm{df}=35, P<0.01)$; however, in 2008, the correlation was rather low (Pearson correlation, $r=0.25$, $\mathrm{df}=56$; nonsignificant).

To examine the possibility that insects such as the greater date moth might be causal agents of bunch drop, we performed field experiments to exclude potential insect pests with different insecticide treatments. As shown in Figure 3, repeated soil applications of imidacloprid or crown sprays with a mixture of chlorpyrifos, lufenuron, and dichlorvos did not reduce the level of bunch drop in two treated orchards in 2005. Similar results were obtained in an experiment conducted in 2006 (data not shown). Furthermore, $A$. sabella and other insects were only rarely detected in the damaged fruit stalks.

On the other hand, tissue decay was detected in many of the freshly fallen fruit stalks. Thirty-one cultures of $F$. proliferatum were isolated from infected tissue and subsequently verified as $F$. proliferatum, using a speciesspecific PCR detection method (Mulè et al., 2004). Because $F$. proliferatum is a known pathogen of date palm (Abdalla et al., 2000; Armengo et al., 2005), bioassays were conducted to determine the pathogenicity of these

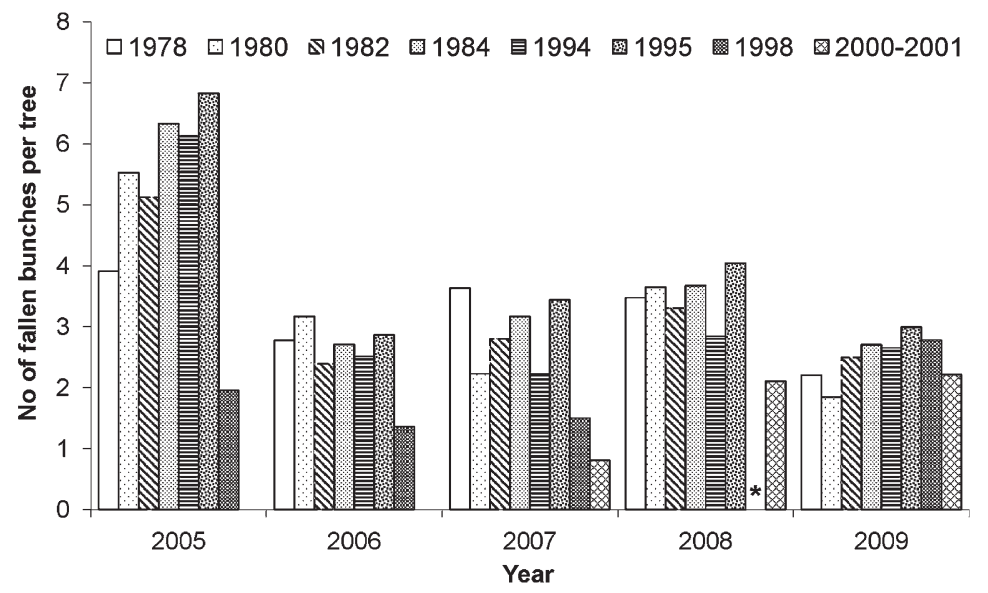

Fig. 2. Average bunch drop during 2005 to 2009 in eight date palm plots of different ages planted along the northern shore of the Dead Sea (Almog plantations) between 1978 and 2001. Plots are marked according to their planting year. *Data not recorded.

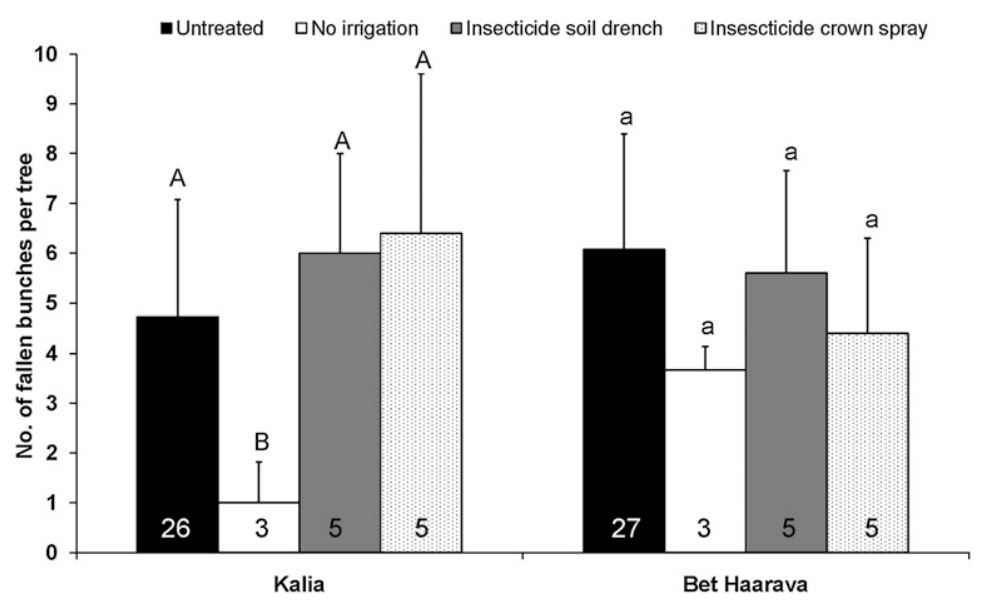

Fig. 3. Effects of irrigation and pest management (Confidor treatment as a soil-drench or Dorsan, Match, and Divipan mix as an insecticide spray to the base of the leaves of the crown) on bunch drop at two date palm plantations, Kalia and Bet Haarava, during 2005. Data comprises the average numbers of fallen bunches per tree \pm SE. The numbers within the columns indicate the number of replicates. Different letters represent treatments that are statistically different within each plantation (one-way analysis of variance followed by Tukey honestly significant difference, $P<0.05$ ). isolates on fruit stalks. Fusarium proliferatum isolates were infective when inoculated onto detached immature and mature fruit stalks (Fig. 4). Lesions developed even in the absence of any wounding of the stalks (Fig. 4A). However, this response appeared to be nonspecific, because similar lesions were caused by an isolate of Fusarium oxysporum f. sp. melonis, the causal agent of muskmelon wilt (Fig. 4B).

Fusarium proliferatum isolates grown on artificial medium were found to be sensitive to prochloraz, which completely inhibited growth when applied at $10 \mathrm{mg} \cdot \mathrm{L}^{-1}$ (data not shown). Therefore, several field experiments were carried out to determine whether $F$. proliferatum could be a possible causal agent of bunch drop. Repeated crown applications of prochloraz in 2007, before the emergence of the inflorescences, resulted in a small decrease in the level of damage. However, this decrease was not significant (Fig. 5).

It is possible that the fungicide and insecticide treatments were ineffective because they did not penetrate deep within the center of the crown to protect the inner susceptible tissues. To clarify this issue, crowns of two mature, fruit-bearing date trees were dissected in an attempt to observe damaged fruit stalks during their development and potential causal agents of the damage. More than 30 exposed and unexposed inflorescences were examined in each tree. Only one of these dissected inflorescences had a damaged fruit stalk. Although its spathe was completely intact and mechanically undamaged, the fruit stalk was affected. An unknown species of fusarium was detected on the rotting tissue. Although no insects were visible on this specific fruit stalk, a single larva of $A$. sabella was detected on the spathe of an additional fruit stalk. In the latter case, superficial scars were detected along the fruit stalk, but these did not cause cross-cut. However, bunch drop appears to be a phenomenon that randomly affects date palms, and the two dissected trees may not be representative of the situation. The timing of the dissection may also be critical in detecting the causal agent, and there is uncertainty whether the dissection was timed correctly.

If the major cause of cross-cut is a biological agent, an arthropod, or a microorganism, we would expect to find a non-random distribution pattern of infected palms in time and space. However, the results of a spatial distribution assessment that used a coefficient of dispersion revealed values lower than 1 (0.62 to 0.96 ) suggesting that bunch fall levels are randomly distributed. Furthermore, no correlation was observed among the numbers of bunches that fell from particular trees in 4 consecutive years (Pearson correlation, $r=0.02$ to 0.05 , $\mathrm{df}=380$, nonsignificant). These findings further support the hypothesis that the main cause of bunch drop is not a biological agent (pest or fungal pathogen).

Another possible factor affecting bunch drop may be cracks occurring in the fastgrowing soft tissues of the fruit stalk. Two environmental factors affect the growth rate of the fruit stalk, water status and air temperature. 


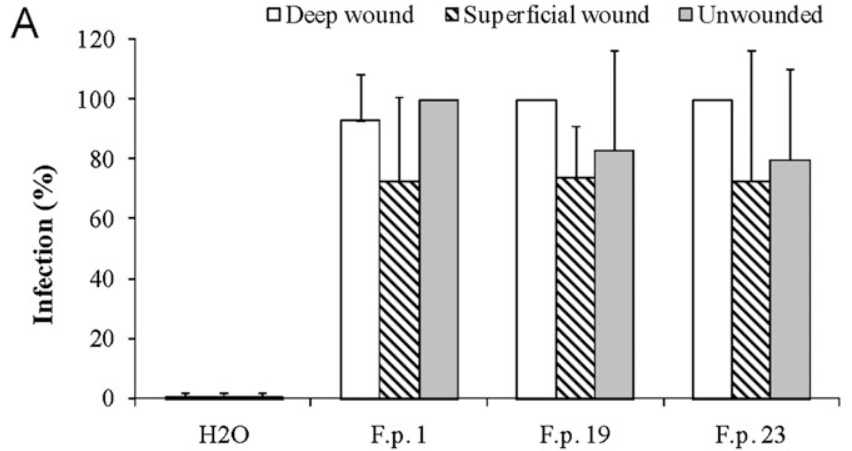

Isolates

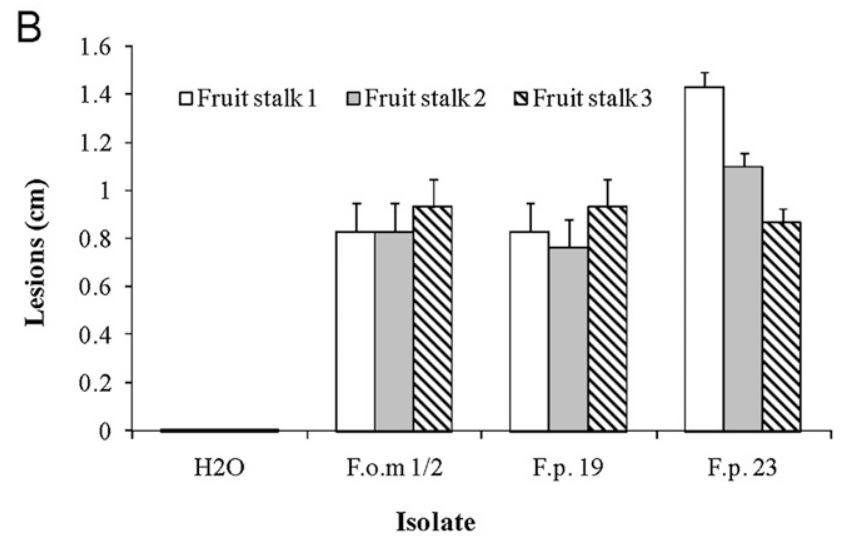

Fig. 4. Effects of artificial inoculation of date palm fruit stalks with Fusarium proliferatum and $F$. oxysporum f. sp. melonis isolates, in vitro. (A) Effect of artificial inoculation of three $F$. proliferatum isolates (F.p. 1, F.p. 19, and F.p. 23) on percentage infection of fruit stalks. $\mathrm{H}_{2} \mathrm{O}$ denotes a waterinoculated control. The isolates were inoculated either without wounding or with a superficial or 2-mm deep wound. (B) Lesion development $(\mathrm{mm})$ on fruit stalks artificially inoculated (without wounding) with two F. proliferatum isolates (F.p. 19 and F.p. 23) and a F. oxysporum f. sp. melonis isolate (F.o.m. 1/2) from muskmelon. $\mathrm{H}_{2} \mathrm{O}$ denotes a water-inoculated control. The data in $\mathbf{A}$ and $\mathrm{B}$ are the average lesion measurements per fruit stalk \pm SD.

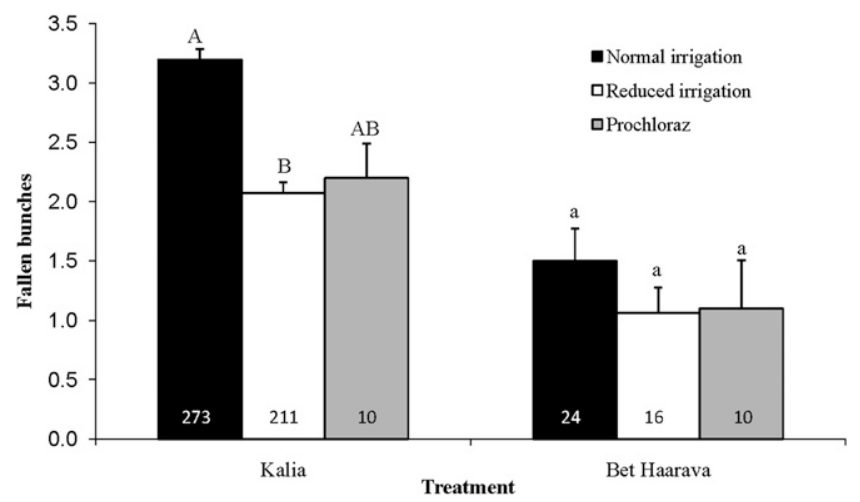

Fig. 5. The effect of reduced irrigation and the fungicide prochloraz crown spray on fallen bunches at two date palm plantations, Kalia and Bet Haarava, in 2007. The data presented are the average numbers of bunches dropped per tree \pm SE. Numbers within the columns indicate the number of replicates. Different letters represent treatments that are statistically different within each plantation (one-way analysis of variance followed by Tukey honestly significant difference, $P<0.05$ ).

Although we could not manipulate the temperature conditions of the palm trees growing in the orchards, we were able to modify irrigation levels. Initially, we completely discontinued irrigation of three trees in two orchards during the inflorescence-growing periods. This extreme treatment resulted in a significant re- duction in bunch drop in one orchard (Fig. 3; Kalia) and in some reduction, albeit insignificant, in the other (Fig. 3; Bet Haarava). Similar reduction in bunch drop was observed in 2006 , when irrigation levels were reduced by $80 \%$ to 16 trees per orchard in Kalia and Bet Haarava. Lower spear leaf and fruit stalk growth rate was observed in the water deficient trees (Fig. 6A). Average reductions of $5 \%$ ( 80 versus $84.5 \mathrm{~cm}$ of growth in $24 \mathrm{~d}$ ) and $14 \%$ (37 versus $43 \mathrm{~cm}$ in 19 d) in fruit stalk growth were measured in Kalia and Bet Haarava, respectively. In a largescale experiment performed in 2007, in which irrigation levels of 211 trees in the Kalia orchard were reduced by $80 \%$, we observed a significant decrease in the number of dropped bunches on the trees that received reduced quantities of water (Fig. 5; Kalia). A similar result was obtained in a smaller experiment conducted in Bet Haarava (16 trees with reduced irrigation). However, in this case, the effect of reduced irrigation was not significant (Fig. 5; Bet Haarava).

Because both the fungicide and irrigation treatments seemed promising in reducing the bunch drop phenomenon, we tested for the presence of any additive effect. In 2008 and 2009, a wide-scale experiment was performed in four different orchards involving a total of more than 1500 trees. The use of reduced levels of irrigation altered the soil water potential, which increased with soil depth (Fig. 7). A consistent decrease in the growth rate of the spear leaves was also recorded (Fig. 6B). In three plots (out of four), we detected a consistent, significant reduction in bunch drop in response to reduced irrigation (Fig. 8A-C). However, in one of the plots (Mizpe Shalem in 2008), the initial total level of bunch drop was too low to assess any effect of the treatments. In this same plot in 2009, the reduced irrigation resulted in increased bunch drop (Fig. 8D). This surprising difference in the responses to reduced irrigation in the different plots could be the result of local soil composition and drainage or local microclimate conditions. In fact, the trees in the Mizpe Shalem plots usually flower $\approx 2$ weeks before the trees in neighboring plots. The fungicide treatment did not result in any further consistent reduction in bunch drop as compared with the reduced-irrigated plots. In some cases, this treatment even increased the level of bunch drop, which may be the result of phytotoxicity.

Bunch drop phenomenon apparently occurs deep inside the tree trunk. Although described $\approx 80$ years ago, not much new information accumulated during the years. This study indicates that among the three previously suggested causes of bunch drop (the greater date moth, A. sabella, fungal pathogens, and/or physiological disorders), the main cause, at least in the Dead Sea region, appears to be physiological-mechanical cracks. These cracks presumably occur in the fast-growing fruit stalks. The fruit stalk is very soft before it emerges from between the leaf base. During periods of warm weather, the fruit stalk can grow up to $5 \mathrm{~cm}$ per day (Fig. 6A). The inflorescence's fruit stalk expands rapidly, growing from its base deep within the heart of the palm's crown. However, the emerging spathes have to penetrate through the dense, hard leaf bases. We hypothesize that the pressure from below and resistance from above can cause fractures in the most vulnerable soft tissue of the developing fruit stalk. Reducing irrigation levels slows the growth of 

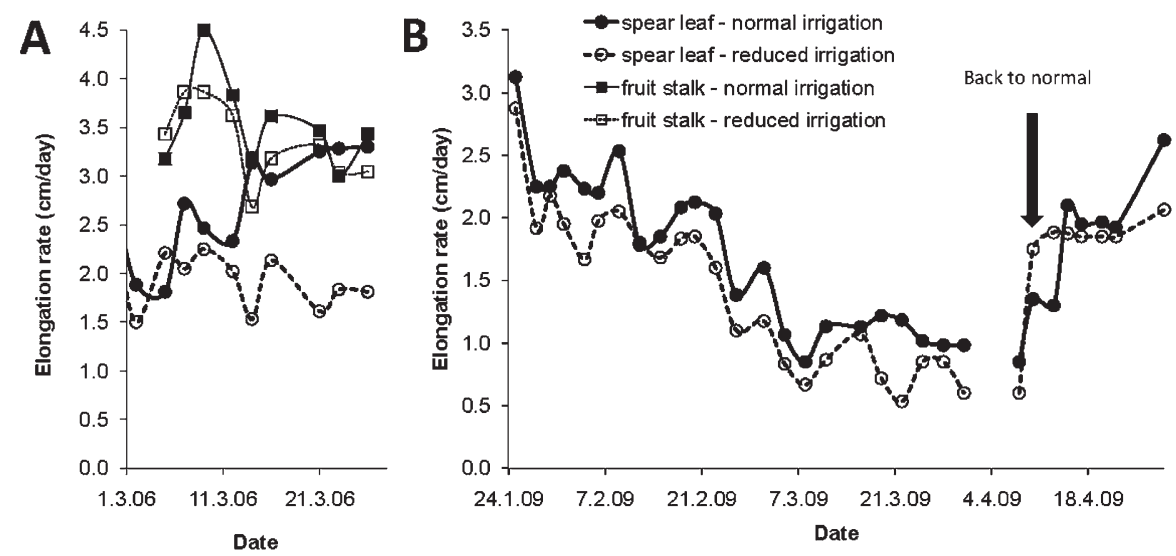

Fig. 6. The effect of reduced irrigation on date palm growth. Data represent the daily average growth of the spear leaves and the fruit stalks of three date palms at the Kalia orchard from 2006 (1 to 26 Mar.) (A) and the spear leaf elongation rate in 2009 (24 Jan. to 29 Apr.) (B). The arrow indicates the date on which normal irrigation was resumed in the treated plot.
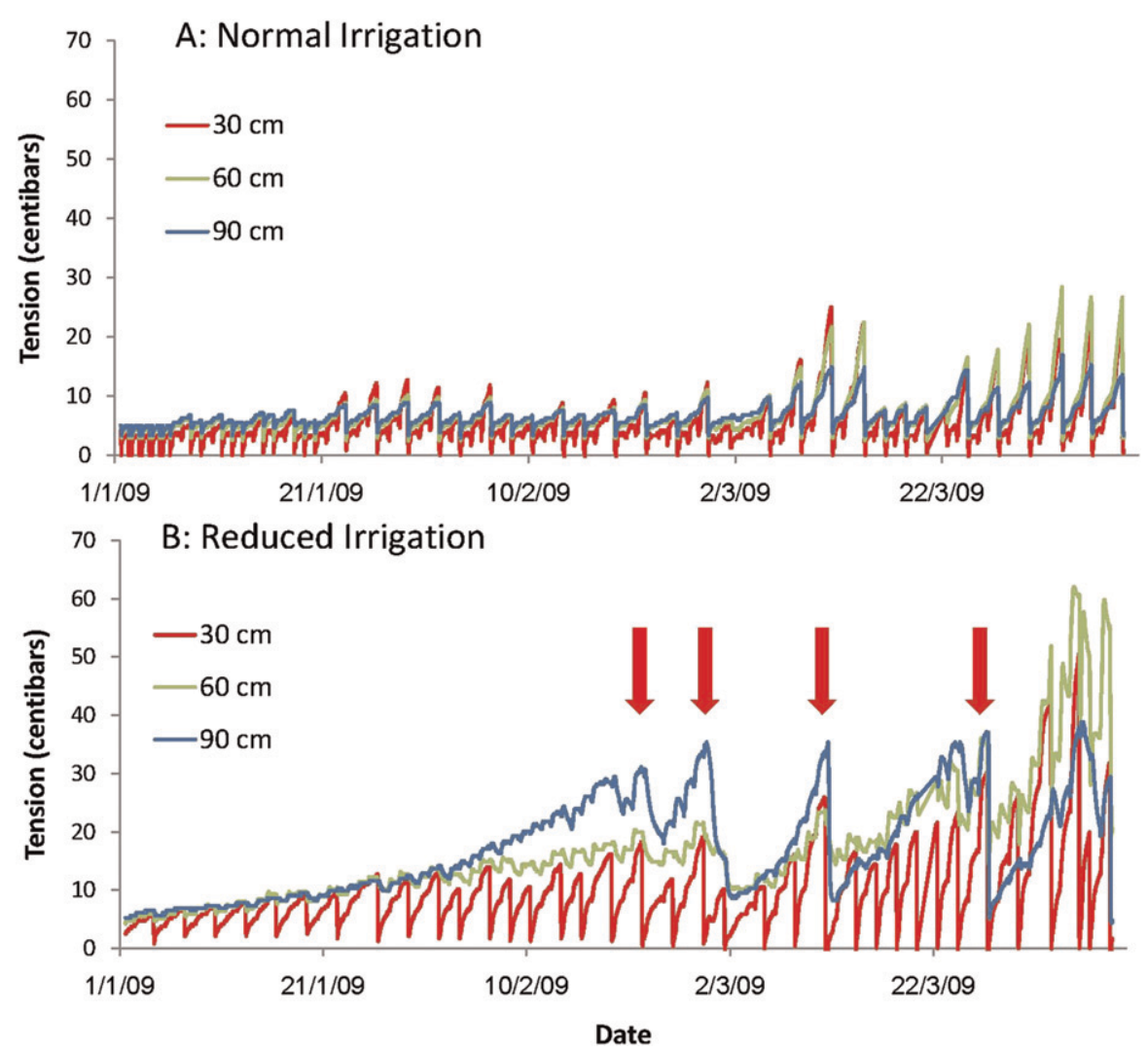

Fig. 7. Effect of reduced irrigation on water tension at three different soil depths. Water tension was measured using one set of tensiometers at each site at depths of 30,60, and $90 \mathrm{~cm}$. Measurements were performed every 15 min from 1 Jan. 2009 through 8 Apr. 2009. The arrows in B indicate rainfall events.

the fruit stalk, enabling proper passage of the inflorescence between the leaf bases, thus decreasing the fracture rate of the stalks. We expect bunch drop to be mainly dependent on cultivar characteristics such as crown density and fruit stalk diameter. The bunch drop phenomenon is common in cultivars such as 'Khadrawi' and 'Sayer' (Bliss, 1937; Brown and Butter, 1936), which are characterized by dense crowns with short internodes between leaf bases. On the other hand, 'Medjool' that does not have a dense crown, has slender fruit stalks that most likely increase its sensitivity. The phenomenon is almost nonexistent in cultivars with thicker fruit stalks such as 'Barhee', 'Deglet Noor', and 'Hayani' grown under similar climatic conditions.

Date palm is a thermophilic, drought-tolerant plant. Date trees can survive on very little water. These characteristics have made the date palm the major fruit crop in desert oases. However, date palm needs sufficient water of acceptable quality to reach its full potential yield (Liebenberg and Zaid, 1999). In date cultivation, a factor of 0.65 to 0.75 of the measured evapotranspiration is generally used. Many Israeli palm growers tend to overirrigate beyond this recommendation (safety factor) in response to significant uncertainties regarding its suitability for specific orchards. These safety factors are justified based on the limited nature of both the current knowledge and water stress assessment tools available for commercial use. In warm, arid regions of Israel, in which the potential evapotranspiration measured from a Class A pan is $\approx 2.7 \mathrm{~m} /$ year, annual irrigation levels can reach $25,000 \mathrm{~m}^{3} \cdot \mathrm{ha}^{-1}$ (Bernstein, 2004). In a number of countries around the world, similar and even higher levels are used (Liebenberg and Zaid, 1999). Experiments to calibrate date palm irrigation levels on a monthly basis have been performed (Tripler et al., 2007). In the present study, we reduced the irrigation only during the coolest season of the year, from December through mid-April. The reduction of irrigation levels reduced bunch drop. This reduction also saved a significant amount of water, which is usually scarce in most date-growing regions.

Insufficient quantities of water can damage both vegetative growth and fruit production. Throughout our experiments, over 4 consecutive years and from plots in different orchards, we did not detect any reductions in the number of inflorescences, yield, or fruit size. However, a multiseason experiment is necessary to ensure that negative effects do not appear by following such an approach.

If reduced irrigation is timed appropriately, no obvious negative effects are expected. During the development of the bunch stalk, the fruitlets barely grow in size and are probably not a major sink for water. In contrast, after the end of fruit stalk elongation (the second half of April), there is a rapid increase in fruit size. We expect that limiting water quantities during this phenological stage would inhibit fruit development and could result in smaller fruits and dropped fruit, reducing total yields. Farmers should be cautioned not to limit water supply during this period.

It should be noted that the manipulation of irrigation levels performed in this study was not designed to improve irrigation efficiency. Before implementing this approach commercially, additional research, calibration of irrigation levels, and determining the appropriate duration of the treatment (both the initial and final period of reduced irrigation) should be performed.

To conclude, apart from the sporadic effects of the greater date moth and the pathogenic fungus $F$. proliferratum, in most cases, manipulation of irrigation levels decreased the bunch drop phenomenon. In addition to reducing bunch loss, this approach also saves water. Still, the impact of irrigation on bunch drop in date palms is expected to vary depending on abiotic factors such as climatic as well as soil conditions and biotic factors such as cultivar type and the presence of pests and pathogens. 


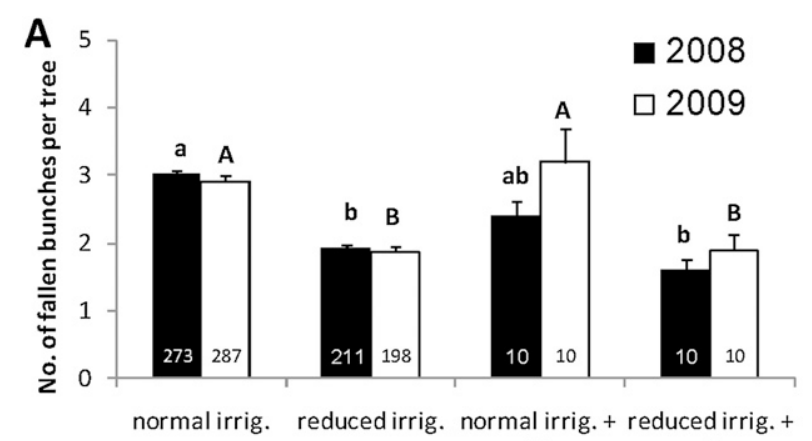
prochloraz prochloraz

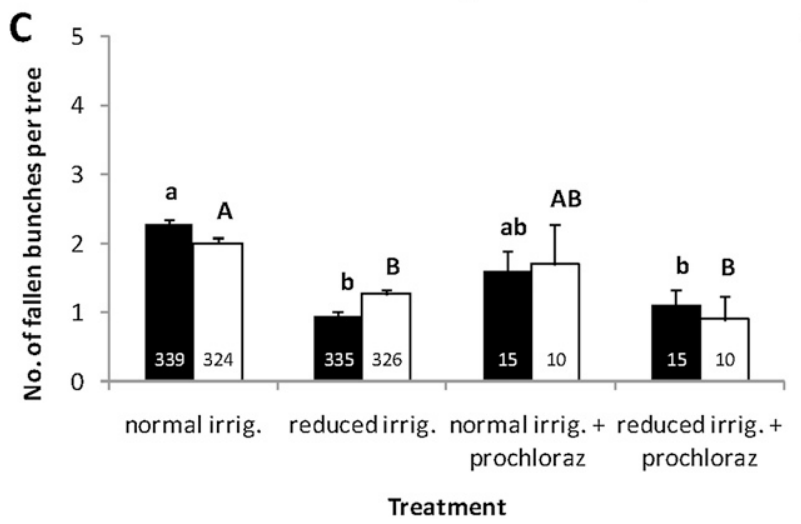

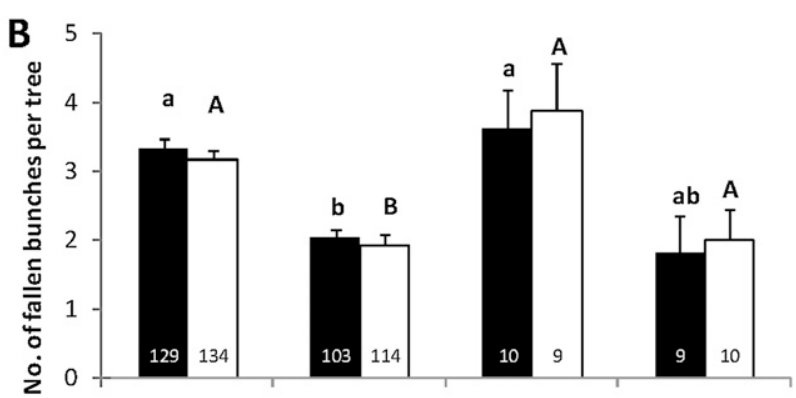

normal irrig. reduced irrig. normal irrig. + reduced irrig. + prochloraz prochloraz

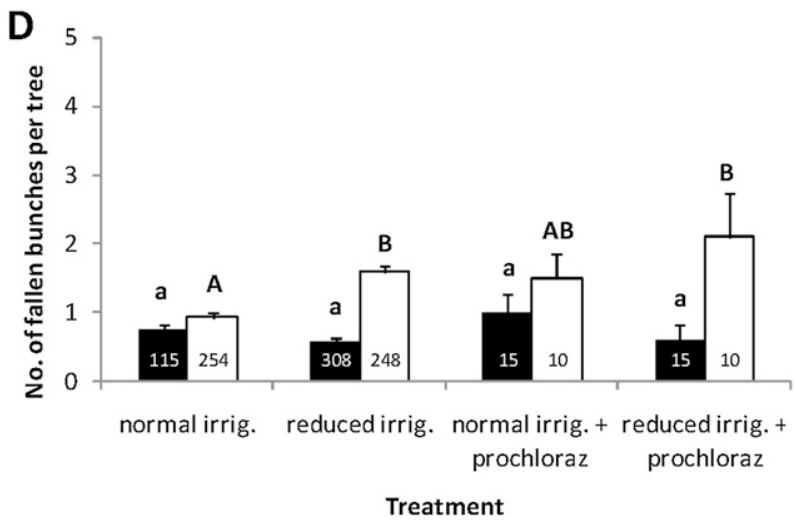

Fig. 8. Effects of reduced irrigation and the fungicide prochloraz crown sprays on bunch drop at four date palm plantations: (A) Kalia; (B) Bet Haarava; (C) Almog, and (D) Mizpe Shalem during the years 2008 to 2009. Black and white bars represent data from 2008 and 2009, respectively. The data present the average number of fallen bunches per tree \pm SE. Numbers within the columns indicate the number of replicates. Different letters represent treatments that are statistically different within each plantation and year (two-way analysis of variance followed by Tukey honestly significant difference, $P<0.05$ ).

\section{Literature Cited}

Abdalla, M.Y., A. Al-Rokibah, A. Moretti, and G. Mulè. 2000. Pathogenicity of toxigenic Fusarium proliferatum from date palm in Saudi Arabia. Plant Dis. 84:321-324.

Armengo, J., A. Moretti, G. Perrone, A. Vicent, J.A. Bengoechea, and J. Garcia-Jimenez. 2005. Identification, incidence and characterization of Fusarium proliferatum on ornamental palms in Spain. Eur. J. Plant Pathol. 112:123-131.

Bernstein, Z. 2004. The date palm. Israeli Fruit Board, Tel Aviv, Israel [in Hebrew].

Bliss, D.E. 1937. Crosscut in the fruit stalks of date palms. Date Palm Growers Institute 14:8-11.

Brown, J.G. and K.D. Butter. 1936. Inflorescence blight of the date palm. Phytopathology 26:88 (abstr.).

Carpenter, J.B. and H.S. Elmer. 1978. Pest and diseases of the date palm. U.S. Department of Agriculture Handbook No. 527, Washington, DC. p. 42.

Chao, C.T. and R.R. Krueger. 2007. The date palm (Phoenix dactylifera L.): Overview of biology, uses, and cultivation. HortScience 42:10771082 .

Dransfield, J., N.W. Uhl, C.B. Asmussen, W.J. Baker, M.M. Harley, and C.E. Lewis. 2008. Genera palmarum: The evolution and classification of palms. Kew Publishing, Kew, UK.

Liebenberg, P.J. and A. Zaid. 1999. Date palm irrigation, p. 130-143. In: Zaid, A. (ed.). Date palm cultivation. Plant Production and Protection Paper No. 156. FAO, Rome, Italy.

Mulè, G., A. Susca, G. Stea, and A. Moretti. 2004 A species-specific PCR assay based on the calmodulin partial gene for identification of Fusarium verticillioides, $F$. proliferatum and F. subglutinans. Eur. J. Plant Pathol. 110:495502.

Nash, S.N. and W.C. Snyder. 1962. Quantitative estimations by plate counts of propagules of the bean rot fusarium in field soils. Phytopathology $73: 458-462$

Okko, O. 2004. Diseases of the date palm, p. 463 485. In: Bernstein, Z. (ed.). The date palm. Israeli Fruit Board, Tel Aviv, Israel [in Hebrew].
Sokal, R.R. and F. Rohlf. 1981. Biometry: The principles and practice of statistics in biological research. 2nd Ed. W.H. Freeman, San Francisco, CA.

Stoler, S. 1977. Date palm cultivation in Israel. Hakibbutz Hameuchad, Tel Aviv, Israel [in Hebrew].

Tomlinson, P.B. 1990. The structural biology of palms. Oxford Science Publications, Oxford, UK.

Tripler, E., A. Ben-Gal, and U. Shani. 2007. Consequence of salinity and excess boron on growth, evapotranspiration and ion uptake in date palm (Phoenix dactylifera L., cv. Medjool). Plant Soil 297:147-155.

Zaid, A. and P.F. De Wet. 1999. Botanical and systematic description of the date palm, p. 29 44. In: Zaid, A. (ed.). Date palm cultivation. Plant Production and Protection Paper No. 156. FAO, Rome, Italy.

Zaid, A., P.F. De Wet, M. Djerbi, and A. Oihabi. 1999. Diseases and pests of date palm, p. 223 287. In: Zaid, A. (ed.). Date palm cultivation. Plant Production and Protection Paper No. 156. FAO, Rome, Italy. 